\title{
La importancia de la tecnología para el ámbito de la comunicación
}

\author{
María Teresa Pellicer Jordá \\ Universidad de Murcia \\ maite.pellicer@um.es
}

\section{Resumen}

La comunicación ha ido ligada siempre a los cambios tecnológicos, los cuales han permitido grandes avances en el campo de los mass-media.

Palabras clave: comunicación, tecnología, historia.

The importance of the technology for the area of the communication

\begin{abstract}
The communication has gone tied always to the technological changes, which have allowed big advances in the area of the mass-media.
\end{abstract}

Key words: communication, technology, history.

Referencia normalizada:

Pellicer Jordá, M. T. (2013) La importancia de la tecnología para el ámbito de la comunicación. Historia y Comunicación Social. Vol. 18 Nº Especial Octubre. Págs. 481-489.

Sumario: 1. Introducción. 2. Metodología. 3. Comunicación y tecnología. 4. Conclusiones. 5. Referencias bibliográficas.

\section{Introducción}

La comunicación como proceso humano ha cambiado de forma sustancial con la aparición de los medios de comunicación de masas. De hecho, se pasó de una comunicación principalmente oral a una comunicación escrita, que más tarde alcanzó la categoría de audiovisual. Esto supuso un cambio, no sólo en la forma de comunicación en esencia, sino en los códigos utilizados y en la configuración del tradicional esquema de emisor-mensaje-receptor. Pero además, se introdujo una serie enorme de variaciones en el canal, ya que los medios de comunicación se erigían como un gran canal infinito, en el que estaba presente el ruido- a veces demasiado- y que permitía multiplicar el número de receptores hasta límites incalculables. 
Lo cierto es que todos esos cambios de los que hablamos han sido posibles gracias a los avances tecnológicos, que son los que dieron lugar a la aparición de los medios de comunicación antes y ahora. Avances tan importantes como la televisión o la radio a la carta son dos ejemplos que acreditan esa relación tecnología comunicación de la que hablamos

\section{Metodología}

Para analizar todas las cuestiones que acabamos de plantear hemos analizado las opiniones y cuestiones planteadas por distintos autores, de reconocido prestigio en este ámbito, y que nos permitirán alcanzar conclusiones de gran interés.

\section{Comunicación y tecnología}

La comunicación y la tecnología constituyen un binomio importantísimo en nuestro tiempo. Nadie puede imaginar su vida sin la prensa, radio, televisión o Internet. Los medios de comunicación social son un imprescindible en nuestro tiempo y, además, se ha fundido con la publicidad, la gran financiadora de los medios y una de las bases del sistema capitalista en el que nos encontramos. Como explica Benavides:

La sociedad del conocimiento ha convertido a los medios y, sobre todo a la información, en el catalizador de cualquier acontecimiento y en el prescriptor de la realidad; pero por el otro lado, los recursos de la práctica publicitaria han colonizado los diferentes soportes mediáticos haciendo de ellos unos instrumentos explícitos para hacer publicidad y espectáculo de la realidad que se transmite (Benavides, 2004. Pág. 94-95)

¿Qué son los deportes, las noticias, los comentarios, el trabajo de los productores de la tv americana? Se preguntaba el comentarista de televisión Howard Cosell. "Sencillamente todo aquello que sirva para rellenar los espacios vacíos entre dos páginas de publicidad o entre dos spots televisivos (Soria, 1999. Pág. 161)”. Como decíamos, publicidad y medios de comunicación se han convertido en una pareja muy rentable y esa rentabilidad es la que también permite financiar el avance tecnológico. Como afirma Sánchez Guzmán:

La crítica que viene soportando la publicidad desde los albores de su nacimiento como tal, a principios del siglo XIX, ha pretendido ocultar, como una cortina de humo impregnada de una suerte de olor a azufre diabólico, su verdadera misión económica y sus implicaciones sociales positivas en un mundo que ya no es posible concebir sin la existencia de mensajes publicitarios. Por muchos apocalípticos que sigan lanzando sus diatribas contra lo que es, ni más ni menos, una importante y decisoria tarea que ha de llevar a cabo toda empresa que decide luchar contra la fuerte competencia que rige en los mercados actuales y que, de rechazo, permite que la información sobre los hechos cotidianos pueda ser difundida entre el público a un precio mínimo, gracias 
al importante recursos financiero que suponen los ingresos por publicidad para todos los medios de comunicación (Sánchez Guzmán, 1993. Pág. 19).

Lo cierto es que la tecnología tiene mucho que ver en los medios y en las múltiples posibilidades que ofrecen, así como en las alianzas que tienen con otros sectores y disciplinas académicas.

\subsection{Un breve repaso por la historia del binomio comunicación y tecnología}

Si hacemos un breve repaso por la historia de la comunicación, podemos considerar la imprenta como el hito tecnológico principal en lo que a cultura y educación se refiere y, además, pieza angular para los medios de comunicación. Gracias a la imprenta apareció el primer medio de comunicación de masas, la prensa (Bordería, 1996. Pág. 294). La imprenta permitió la producción en serie de la cultura, la educación y de la información. Como explica Bordería:

Antes de la aparición y del desarrollo de la imprenta, los hombres de alta cultura no compartían ningún marco estable de referencias espacio-temporales; hizo falta un siglo de tipografía para que las cronologías, las topografías, los datos y los materiales arqueológicos quedasen fijados $\mathrm{y}$, a la vez, universalizados para el conocimiento. (Bordería, 1996. Pág. 181).

De este modo, la imprenta supuso un avance importantísimo y se convirtió en la herramienta fundamental para unos incipientes medios de comunicación, que aprendían a comunicar y transmitir informaciones.

En cualquier caso, la imprenta no es sino uno más de los muchos avances tecnológicos que, aplicados a los medios, han dado lugar a la configuración actual. La electricidad, por ejemplo, "va a proporcionar una nueva dimensión al mundo de la comunicación al eliminar la distancia entre el hecho noticiable y los centros interesados en su recepción, lo que ofrece la base para el nacimiento del telégrafo y de las primeras agencias telegráficas" (Bordería, 1996. Pág. 299).

Cada avance tecnológico suponía una mejora en la prensa de masas. Las mejoras tecnológicas permitieron hacer más periódicos y más rápidos. Aparece el teléfono en las redacciones (inventado por Bell en 1876), la linotipia (1886) y la fotografía.

Más tarde aparecen otros medios, como la radio, "medio que técnicamente nacen a finales del siglo XIX pero que adquirirán su verdadera fisionomía y dimensión a partir de las primeras décadas del siglo XX (Bordería, 1996. Pág. 348)”. La radio ofrecerá unas ventajas que la prensa no puede igualar. En primer lugar, gracias a la tecnología que sustenta este medio, carece de fronteras. "La posibilidad de poder escuchar lo que se dice por radio en todo el mundo es un poder tan grande que a él se debe en gran parte la caída de regímenes políticos que parecían eternos, como los comunistas del Este europeo" (Blázquez, 2002. Pág. 611). A esta característica se suma la inmediatez, que permite retransmitir una noticia en el mismo momento en el que el acontecimiento está ocurriendo y el bajo coste económico que supone para el receptor, ya que éste sólo tiene que invertir en el aparato de radio. Los periódicos 
suponían en desembolso económico diario de los lectores mientras que la radio suponía una única inversión, además de bajo coste. A estas ventajas se suman que la radio permite realizar otras tareas mientras se escucha y el sentimiento de compañía que ofrecen a muchos oyentes, sobre todo a aquellos que, por circunstancias de la vida, padecen la temida soledad. De este modo, un avance tecnológico como el que supuso la aparición de la radio, se convirtió en una auténtica revolución para los ciudadanos, que veían como la radio se convertía en una parte muy importante, y a veces imprescindible, de su vida.

Como afirma Briggs, "la tecnología cambia tan rápidamente y su presencia es tan penetrante que la historia más amplia queda olvidada y, cuando se la examina, no todo converge (Briggs, 2002. Pág.356)”. A la radio le siguió la televisión, que superaba algunas de las ventajas que ofrecía la radio, aunque ésta siempre tendrá algunas bondades inigualables por otros medios. La televisión supuso una auténtica revolución en el ámbito de los medios de comunicación. Se convirtió en una pieza fundamental del sistema democrático y en un servicio público. Como afirma Pizarroso:

A medida que la televisión (...) fue comiendo terreno a la prensa escrita, primero en los años 60 por lo instantáneo de sus noticias en imágenes, lo que obligó a ésta a explicar e interpretar las informaciones, lo que la dejo sin apenas defensas propias, el medio escrito se vio abocado a desarrollar sus formas expresivas y de representación teniendo en cuenta la imagen y sirviéndose de las tecnologías combinadas que permitían un tratamiento de mayor eficacia comunicativa (Pizarroso, 1994: Pág. 243).

La televisión, con una tecnología mucho más compleja y cara que la conocida hasta ahora en prensa y televisión, ofrecía algunas ventajas similares a las de la radio, como era la inmediatez, su capacidad para hacer compañía al espectador, su riqueza de recursos o lo económica que suponía, ya que, al igual que la radio, sólo suponía el desembolso del aparato de televisión (aunque su precio era bastante superior al del aparato de radio). En cualquier caso, la tecnología de la televisión permitía al espectador estar en medio del escenario de la noticia, verlo y oírlo todo, presenciar casi el acontecimiento. La televisión se convirtió pronto en el medio estrella, rey del entretenimiento y de la información. La radio siempre siguió ostentando la consideración del medio con mayor credibilidad y objetividad. La tecnología televisiva ha ido avanzando a pasos agigantados y permitió, por ejemplo, pasar del blanco y negro al color, a la alta definición, a la televisión a la carta y muchos más recursos que la televisión ha introducido en sus programas y series.

Otro medio revolucionador fue Internet, con sus múltiples posibilidades. De hecho, todas las cadenas de televisión, periódicos y emisoras de radio cuentan con Internet como un recurso que les permite convertirse en grupos multimedia. Un periódico puede convertirse en televisión colgando en su web vídeos, y lo mismo le ocurre a la radio. La televisión, por su parte, se convierte también en prensa, colgando en su web noticias textuales, que se suma a la amplia oferta audiovisual que tienen. "Cuando Internet, la red global, está modificando las bases del acceso a la información, la tecnología del periodismo de los años 70 nos hace pensar en la prehistoria (Piza- 
rroso, 1994. Pág. 261)". Como dice Pizarroso, "la paradoja de esta mutación cultural es que puede significar el fin del periodismo industrial de base 'taylorista' al hacer posible el retorno a una concepción periodística artesanal, recreada sobre la base de las tecnologías interactivas de la información y la comunicación (Pizarroso, 1994. Pág. 263)". Y es que Internet ofrece mucho más, permite a los usuarios convertirse en periodistas, expertos en moda, escritores refinados. Los blogs, por ejemplo, son uno de los servicios que ofrece Internet y que han supuesto una revolución informativa. El ciudadano, por su parte, puede informarse de forma gratuita (la única inversión es la del aparato receptor de la señal- ordenador, móvil, tablet, etc- y la cuota de pago de Internet) o acceder a un universo infinito de imágenes, audios, etc. Entre las grandes revoluciones de Internet de los últimos años, encontramos las redes sociales, que han supuesto un auténtico boom entre los internautas y que se han convertido en la fuente de información de muchas de las noticias que vemos en los medios de comunicación. Ahora bien, en relación a Internet, Ramonet habla de una ilusión y dos amenazas. Como ilusión menciona la democracia electrónica potencial.

Llegará el día en que los ciudadanos podrán votar sus decisiones políticas en su computadora evitando la influencia de los grupos de presión contrarios. Pero esta posibilidad lleva anejo el peligro del llamado linchamiento electrónico y restauración del principio de la pasión. Cada uno podrá votar de acuerdo con su estado pasional, lo que podría degenerar en el cibercretinismo" (...) Las dos amenazas siguientes serían: "Internet se presenta como una tentación irresistible para los mastodontes de la comunicación de crear el monopolio absoluto de las redes. (...) Como consecuencia de la lucha de intereses y de los supermonopolios surge la otra gran amenaza. Consiste en la creación de nuevas desigualdades entre ricos usuarios y pobres manipulados. Internet puede contribuir a agrandar aún más las diferencias sociales clásicas entre ricos y pobres a escala planetaria (Blázquez, 2002. Pág. 752-753).

De este modo, la tecnología es la que permite que cada medio supere al anterior, en muchas ocasiones, o lo complemente. El directo sólo pueden ofrecer la televisión y la radio y esto da lugar al envejecimiento de la prensa diaria, "forzosamente retrasada respecto a los hechos" (Blázquez, 2002. Pág. 25).

Pero lo cierto es que la tecnología no sólo afecta a los medios como tal, sino que también etiqueta a la sociedad del momento. Como dice Blázquez:

Mientras que la invención técnica se produce por oleadas y requiere el sostén de la movilización de capital, se tiende a etiquetar a la sociedad de acuerdo con lo que, por una variedad de razones, parece ser su tecnología de comunicaciones dominante. La era de los ferrocarriles, (...) la era de la radio, la era de la televisión... (Briggs, 2002. Pág. 295).

\section{Como afirma Castell:}

La evolución de la sociedad, desde la emergencia de la modernidad con la primera Revolución Industrial (a finales del siglo XVIII) sería la siguiente: sociedad industrial (se tiene acceso a los bienes producidos por otros), sociedad postindustrial (nace después de la II Guerra Mundial, los individuos acceden también a los servicios prestados por otros) y la sociedad d de la información ( a partir de la década de los 
70- siglo XX- se tiene acceso a los bienes, servicios e información generada por otros) (García, 2007. Pág. 98).

\subsection{Nuevos medios, nuevas tecnologías y nuevas formas de entender}

Lo cierto es que los avances técnicos dieron lugar a nuevos medios, pero no sólo eso, sino que dieron lugar a nuevas formas de entender la sociedad. Como dice Leonarda García:

La inmediatez en la consulta de la información, la difusión de la misma entre los propios usuarios, la multiplicidad de fuentes posibles sobre cualquier tipo de temática, la posibilidad de crear/consultar/enviar la información de manera multisoporte... provocan una radical transformación, entre otras, en la transmisión del saber (García, 2007. Pág. 100).

Cambios que también dieron lugar a nuevas formas de entender el trabajo en los propios medios. En primer lugar en la forma de gestionar las empresas de comunicación. Como dice Aznar:

La aplicación a los periódicos de las nuevas tecnologías del vapor y la electricidad requerían inversiones cada vez mayores, que estaban al alcance de muy pocos. El editor se fue convirtiendo así en un empresario o capitalista industrial (o en un grupo ideológico), dispuesto a obtener beneficios o influencia a través de la prensa (Aznar, 1999. Pág. 104).

\section{Como explica Bonete:}

Los medios audiovisuales en las sociedades democráticas se desarrollan en un marco de libre mercado, donde existe la ley de la oferta y la demanda. La estructura empresarial- como ya se indicó- condiciona claramente los contenidos difundidos en los medios audiovisuales, así como las líneas de investigación y aplicación tecnológica de tales medios. En este contexto han surgido regulaciones con la pretensión de establecer claramente que, a pesar de su necesario marco empresarial, los medios audiovisuales no han de centrarse exclusivamente en la búsqueda de los mínimos costes. (...) Por ello, la legislación vigente en nuestro país expresa que los medios audiovisuales son un servicio público esencial, entendiendo por ello, no su forma de financiación desde los presupuestos del Estado, sino sobre todo, la conciencia de que los medios se legitiman en tanto en cuanto contribuyen a la difusión de contenidos educativos y culturales con los cuales se potencia el desarrollo intelectual e incluso moral y político de los ciudadanos (Bonete, 2000. Pág. 35).

La propia estructura empresarial a la que han dado lugar los medios de comunicación, considerados un servicio público esencial para los ciudadanos, da lugar a un debate ético eterno entre la necesidad de cumplir con los objetivos económicos propios de una empresa y con los objetivos informativos y de servicio a los que les obliga su propia condición.

Los receptores también tuvieron que adaptarse a los cambios tecnológicos y, por ejemplo, tuvieron que aprender a leer nuevos códigos. Como afirma Pizarroso: 
Algunos de los elementos prestados del lenguaje propio y de las potencialidades específicas del cómic, la radio, la televisión o la informática, en buena parte también gracias al desarrollo de las nuevas tecnologías, permitieron que los códigos textuales y gráficos de los diarios se ampliaran y diversificaran. Por ejemplo, el salto de escenarios en el relato de un acontecimiento televisado, gracias a diversas cámaras, no sólo podría suplirse con una buena crónica, sino también mediante el grafismo informativo en el cual se combinan dibujos, detalles, explicaciones, cronología, etc, a modo de una historieta ilustrada de media o 1 página; es decir, el reportaje se complementaba con una película de los hechos, donde además de leerse, se veía e incluso se escuchaba (...) la narración de la noticia. Por otro lado, los elementos expresivos de los estándares audiovisuales, incluyendo el de los ordenadores, o sus aspectos de servicio, podrían recuperarse y reciclarse para aplicarlos a los diarios (Pizarroso, 1994. Pág. 244).

Estos cambios supusieron nuevas rutinas profesionales para los periodistas y trabajadores de los medios de comunicación. Como dice Ballesta, "la convergencia tecnológica tiene también sus consecuencias en el trabajo del periodista", ya que lo llevan a "elaborar la información de manera específica para cada soporte" (Briggs, 2002. Pág. 47).

\section{Conclusiones}

Medios e información son fundamentales en la sociedad actual, hasta el punto de ser considerados el cuarto poder. En este sentido, Bordería afirma que "en esta sociedad nueva, los detentadores del saber, esto es, del máximo de información, detentan por consiguiente el poder" (Bordería, 1996. Pág. 414). Para otros los medios son un contrapoder que tiene que vigilar y controlar a los políticos. En cualquier caso, es indudable la influencia de los medios en la sociedad. Castell dice que "debido a la convergencia de la evolución histórica y el cambio tecnológico, hemos entrado en un modelo puramente cultural de interacción y organizaciones sociales" (García, 2007. Pág. 102). Si tenemos en cuenta, tal y como hemos explicado en párrafos anteriores, que la tecnología tiene mucho - o más bien todo- que ver para que los medios sean lo que son-, podremos decir que el que dispone de la tecnología tiene mucho que decir en este asunto. En este sentido, Suárez afirma que una de las causas de la concentración del poder económico y simbólico es la "posesión de las nuevas tecnologías de información digital por el capital privado (Suárez, 2006. Pág. 33). Tecnología y comunicación se necesitan. Como dice Borderia,

El industrialismo necesita desarrollo tecnológico y comunicacional para sobrevivir. Debido a ello, a lo largo de la pasada centuria, podemos censar una treintena de descubrimientos tecnológicos importantes para la consolidación de la comunicación de masas (Bordería, 1996. Pág. 306).

De este modo, una de las tendencias de los medios de comunicación es la innovación tecnológica. "El paradigma de la tecnología de la información se basa en la flexibilidad”, como dice Castell (Castell, 2007. Pág. 99). 
En cualquier caso, como bien plantea Pizarroso, el debate principal está centrado "sobre las formas que va a adoptar el acelerado proceso de convergencia y conectividad en el futuro". El autor se pregunta ¿de qué forma está impactando la mutación tecnológica sobre el tejido social?, a lo que responde así (Pizarroso, 1994. Pág. 262):

- Actuando en el sentido de favorecer la desterritorialización de la cultura (satélites, Internet).

- Acelerando la crisis del modelo de reproducción cultural asociado al Estado-nación (unidad de mercado y monopolio de la producción simbólica de identificación comunitaria).

- Reforzando la simultaneidad de las lógicas de globalización de los mercados culturales y de una nueva emergencia de la diversidad y favoreciendo una redefinición de la dialéctica global/local.

- Reformulando las realidades nacionales multiculturales y los procesos de mestizaje cultural.

Bordería considera que "uno de los temores que provoca esta revolución -tecnológica-, radica en la posible instrumentación del dominio social por medios tecnológicos avanzados" (1996: 415). Pizarroso añade que algo a tener en cuenta es "la creciente dificultad y competitividad del sector en general y de los medios impresos en concreto. En esta situación, uno de los puntos calientes para los próximos años girará en torno a la oferta de servicios a la carta y a las posibilidades de convertir los periódicos en puntos de venta de servicios" (Bordería, 1994. Pág. 586). En cualquier caso, como bien apunta Ballesta:

Estamos viviendo una época en la que los canales de información y entretenimiento nos desbordan. El exceso de oferta nos obliga a cambiar los hábitos de consumo de la información y del entretenimiento. Sin embargo, llega un momento en el que la variedad se convierte en monotonía. Apenas encontramos diferencias. Los contenidos son muy similares. Por eso son precisamente los contenidos, su calidad y singularidad, el eje de la gran batalla que libran ahora las grandes empresas, las cuales, a su vez, han superado las clasificaciones tradicionales y se han convertido en empresas de información, entretenimiento y telecomunicaciones (IET) (Ballesta, 2002. Pág. 44).

Para finalizar este artículo y como conclusión final del mismo, podemos decir que medios y tecnología van cogidos de la mano en el camino de la modernidad. Los medios de comunicación, tal y como los entendemos hoy en día, no serían posibles sin los avances tecnológicos. Éstos han supuesto cambios muy importantes en la estructura empresarial de unos medios cada vez más influyentes en la sociedad; en la forma de descodificar de los receptores y en la forma en la que los profesionales de la comunicación hacen su trabajo. La tecnología ha demostrado, una vez más, su importancia en la sociedad, en el mercado de trabajo y en el mercado de la información, una información cada vez más tecnológica, en la que los informativos se transforman en "relatos de entretenimiento vestidos en las formas de cinematografía hollywoodiana" (Bordería, 2006. Pág. 30). 


\section{Referencias bibliográficas}

AZNAR, H. (1999) Comunicación Responsable. Editorial Ariel: Barcelona.

BALLESTA PAGA, J. (2002 c) Medios de comunicación para una sociedad global. Universidad de Murcia: Murcia

BENAVIDES DELGADO, Juan. (2004). "La ética y los medios de comunicación en el ámbito de la cultura publicitaria. Una aproximación conceptual". En Zamora, J. A. Medios de comunicación, información, espectáculo y manipulación. Verbo Divino. Navarra.

BONETE, E. (2000) Ética de la comunicación audiovisual. Tecnos: Madrid.

BLÁZQUEZ, N. (2002). La nueva ética en los medios de comunicación. Bac: Madrid BRIGGS, A; BURKE, M. (2002 a). De Gutenberg a Internet. Taurus: Madrid

BORDERIA ORTIZ, E; LAGUNA PLATERO, A; MARTÍNEZ GALLEGO, F. (1996) Historia de la comunicación social. Editorial Síntesis: Madrid.

GARCÍA JIMÉNEZ, L.(2007) Las teorías de la comunicación en España: un mapa sobre el territorio de nuestra investigación (1980-2006). Tecnos: Madrid.

PIZARROSO QUINTERO, A. (1994). Historia de la prensa. Editorial Centro de

Estudios Ramón Areces: Madrid.

RAMONET, I. (2002 d). La tiranía de la comunicación. Editorial Debate: Barcelona. SÁNCHEZ GUZMÁN, J.R. (1993). Teoría de la Publicidad. Madrid: Tecnos.

SUÁREZ, J.C. (2006). Los límites éticos del espectáculo televisivo. Mad: Sevilla.

\section{La autora}

María Teresa Pellicer Jordá es Doctora por la Facultad de Comunicación y Documentación de la Universidad de Murcia. Profesora universitaria. 